\title{
Analyzing Texture in Rock Music: Stratification, CoOrdination, Position, ANd PERSPECTIVE ${ }^{1}$
}

\author{
John Covach
}

This article will explore aspects of texture, a musical dimension that is often overlooked or relegated to secondary status in much music-theoretical and music-analytical writing. ${ }^{2}$ Often when we think of music, and especially when we read it or imagine it in terms of a printed score, we conceive of a kind of a two-dimensional object-perhaps like a painting. We usually assume that there is a particular viewing angle on a painting, and though we may move from side to side as we contemplate it, this is ultimately an expanded single view rather than a number of distinct angles. When it comes to thinking about and listening to musical texture, we might imagine that the best positionacoustically or intellectually-is where everything can be heard equally. And while the sound from the conductor's podium may be ideal, music can also be something more like sculpture or even architecture: there are a number of angles from which to understand a musical texture and we can even in a certain sense »get inside « the music-walk around in it and appreciate it from different perspectives with no particular position taking precedence. In the discussion that follows, it will be useful to distinguish »texture « from »instrumentation, « »orchestration, « or »arrangement. «While these dimensions can be closely linked and even interdependent, texture will here be understood to address the structural relationship of parts or layers in the music to one another-parts or layers that might remain in the same structural relationship even if elements in the instrumentation, orchestration, or arrangement were changed.

1 An earlier version of this article was presented at the conference, Populäre Musik und ihre Theorien, Universität für Musik und darstellende Kunst, Graz, Austria; and as part of the Music Theory Colloquium of the Robert Samels Visiting Scholar Series, Jacobs School of Music, Indiana University, Bloomington.

2 For a thoughtful exploration of texture in classical music, as well as the history of its use as a technical term, see Dunsby (1989). 
This article seeks to encourage a greater awareness of issues of texture, and to emphasize how such an increased awareness can affect the ways in which we hear, perform, imagine, and ultimately analyze music. We will concentrate primarily on examples of musical texture drawn from rock music, though some examples taken from other pop styles are also included. As we examine aspects of musical texture, we will first distinguish between »coordinated « and »stratified « textures, defined by the ways in which elements in a texture can interact structurally. We will then explore the possibility of "positional listening, « with emphasis on how textures can be construed in a variety of ways depending on the listener's and performer's focus of attention. Finally, we will consider the idea of »analytical perspectivism « and examine how various and even contrasting analytical »positions « may be negotiated. All of this will bring us back to the sculpture versus painting analogy, which hopefully will have become a bit clearer along the way.

\section{Approaches to Texture: Oppositions}

A useful distinction may be drawn-if only in a preliminary manner-between what we might call »traditional « and »alternative« approaches to texture. In a traditional approach, we strive to hear all the parts in a texture at once. Certain complex or complicated pieces may make this quite difficult to do (as in four-voice contrapuntal pieces or dense orchestral passages, for instance), but nevertheless we try to hear everything. Even when we cannot quite accomplish this, we still wish we could. In such instances we may adopt the »Ideal Listening Position« (ILP), which means that we-at least implicitlyposit a single position from which to understand the musical texture-a kind of musical God's-eye view. In a traditional approach to texture, all voices are coordinated vertically and thus focusing on the entire texture allows one to perceive and appreciate the coordinated structure. In tonal music, this means that no matter where we might freeze the music as it unfolds, we can always account for how each note is related to the prevailing harmony and/or counterpoint. Dissonance may be controlled, but in any case, we depend on the notion of coordination to determine dissonance and consonance, chord tones and non-harmonic tones. In much atonal and twelve-tone music, coordination is also assumed and we are able to make vertical connections within the texture at any point, finding referential sonorities and motivic relationships between parts, for instance.

An alternative approach arises when we focus on some parts or layers in the texture more than others. Rather than adopting a single ILP, we hear the 
music from a particular point in the texture-and there may be multiple such points within any given texture. This alternative approach is familiar to performers, who frequently listen to the music differently than an audience member would-sometimes by necessity, but also sometimes by choice. The term »position « may be used to capture a conceptual point of orientation in listening (not a specific physical location) and we may call this aspect of the alternative approach »positional listening. «In addition, some textures may be less coordinated than others, consisting of layers that do not reduce down to a single harmony, contrapuntal relationship, or referential sonority or motivic collection. In fact, forcing such a reduction between layers in the texture might threaten to do a certain violence to the music and ultimately misrepresent the listening experience. We may employ the term »textural stratification « to describe this kind of layered texture. We are thus faced with a pair of dualities: coordinated structure versus textural stratification; and ILP versus positional listening.

\section{Textural Stratification}

We will return to positional listening later in our discussion; for now, let us focus on textural stratification. Textural stratification occurs when parts in a texture cannot be satisfactorily reduced to a single coordinated structure. A basic form of this kind of layering has been labeled the »melodic-harmonic divorce. « This term was coined by Allan Moore (1995), who cites Peter Winkler (1978) for noting the idea first in print, though Winkler does not use the term »divorce. «3 David Temperley (2007) and Drew Nobile (2013) have further explored this type of layering. The melodic-harmonic divorce occurs when notes in the melody do not align with the harmony that accompanies them. Example 1 provides Temperley's analysis of Steve Miller Band's »Rock'n Me«

3 As Moore (1995: 189) notes, Winkler describes the independence of the melody from the harmonic accompaniment in Schenkerian terms. In discussing a passage from »The Entertainer « by Scott Joplin, Winkler writes: »The melody simply treats this background harmony as if it were foreground and elaborates it directly. Thus, the background is elaborated in two different ways simultaneously. The ear accepts the clashes along the way because the two parts coincide at the crucial points, and because each part makes sense by itself « (1978: 16). Moore also cites Peter Van der Merwe in a similar context. While considering two excerpts by Franz Schubert, for instance, Van der Merwe remarks: »In these two examples we see melodic patterns beginning to assert their independence over harmonic ones. Instead of the melody simply following prevailing chords, independent melodic patterns begin to appear which live a life of their own regardless of what the harmony happens to be doing« (1989: 226). 
(1976). The harmony to this verse section moves from I to bVII then to IV and back to I in B; the example provides only the move from I to bVII. The melody clearly employs the B-major pentatonic collection, here with an inflected third scale degree, not shown in the example but clear in the recording. The melodic-harmonic divorce arises in measures 3 and 4, where the melody securely remains within the B-major pentatonic collection while the harmony moves to bVII. Any attempt to classify these melodic notes as non-harmonic tones in terms of the bVII harmony seems wrong. Instead, Temperley posits a harmonic layer and a melodic layer, both in B but not reducing down in the way a coordinated texture would.

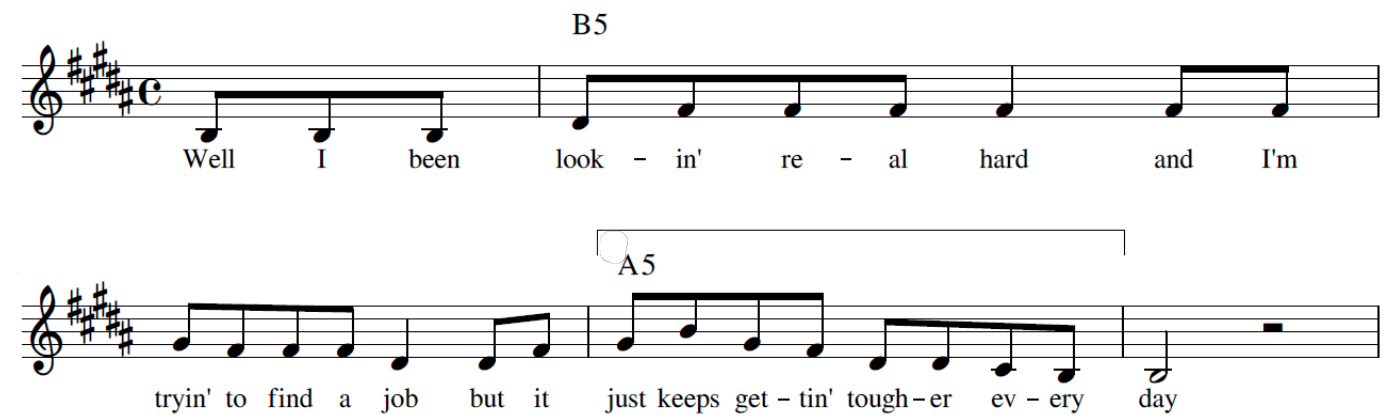

Example 1: Melodic-harmonic divorce in Steve Miller Band's, »Rock'n Me« (1976); Temperley (2007)

The weakness in the melodic-harmonic divorce as Temperley and Nobile use it is that it only accounts for two layers. In their use, the entire accompaniment is reduced down to a single coordinated textural layer, with the melody comprising a second layer when a divorce is present. It can often happen, however, that there are various »divorces « present in the accompaniment as well, and the harmonic-melodic divorce cannot capture this increased level of stratification. Example 2 shows an excerpt drawn from one of the verses in Yes's »Close to the Edge« (1972) (Covach 1997). In this passage, the electric sitar and vocal are in 12/8 while the electric bass and drums are in 4/2. Each part repeats after two measures in its respective meter and the two layers re-align metrically after four guitar/vocal phrases and three bass/drum phrases. While the electric sitar plays a progression that moves from $i$ to bVII to $\mathrm{i}$ and then $\mathrm{ii}$, employing the Dorian mode, the vocal melody does not align within this layer. Against this, the bass line, also in the Dorian mode, does not align with either the sitar part nor with the vocal melody. We thus can detect two layers stratified rhythmically, and a three-way split in the melodic-harmonic domain. The »divorce« exceeds the simple-two-way split 
found in Example 1, providing a clear example of textural stratification. We will return to this example later in our discussion of positional listening.

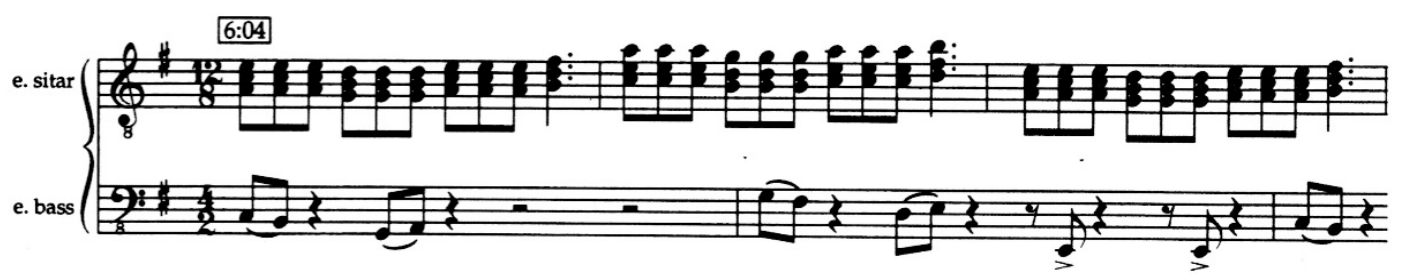

Example 2: Stratification in Yes, »Close to the Edge« (1972); Covach (1997)

Before moving on to consider stratification in more detail, it will be useful to explore some examples in which stratification might seem to be present but is not, giving rise to »apparent stratification. « For these examples, we will move outside the rock style. Example 3 shows the beginning of Harold Arlen and Yip Harburg's »If I Only Had a Brain« from the 1939 film musical, The Wizard of $\mathrm{Oz}$. The brackets in the first two measures draw our attention to a melodic sequence that occurs between these two measures. The first of these outlines a D-major tonic triad, while the second seems to outline a B-minor triad. Against this, however, the harmony outlines a stylistically typical I - ii - $\mathrm{V}$ - I progression. In the second measure of this example, then, the B-minor triad in the melody and the ii to $\mathrm{V}$ movement in the accompaniment might seem to be in conflict. Most listeners, however, are not likely hear such a conflict. Most will hear the B-minor triad notes as harmonic extensions of the ii and $\mathrm{V}$ chord, indicated by the $i^{9}$ and $\mathrm{V}^{11}$ markings in the example. It is worth pausing to consider why this perception of harmonic extension seems so obvious here, when a melodic-harmonic divorce in a similar situation also seemed so obvious in the Steve Miller example. Perhaps these differing interpretations arise because harmonic extensions are normative in musical theater and pop styles of the pre-rock era, while some form of stratification is common in rock; in many instances, style can indeed play a role in determining how we hear textures. »If I Only Had a Brain« is thus a coordinated texture. Non-chord tones in the melody alone, even when they project a melodic sequence seemingly at odds with the supporting harmony, are not enough to result in a melodic-harmonic-divorce nor produce textural stratification. 


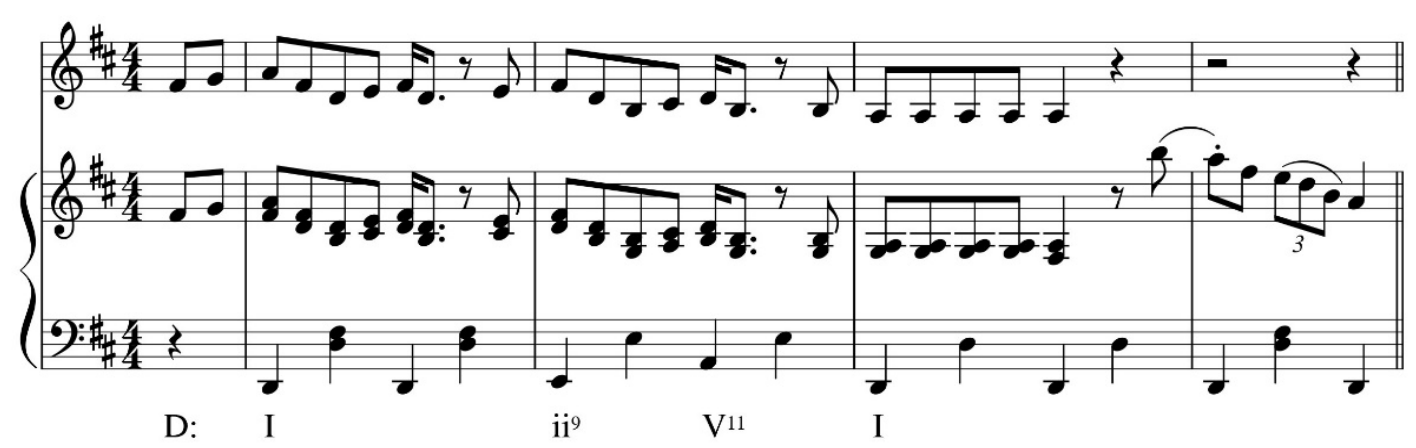

Example 3: »If I Only Had a Brain« (Arlen and Harburg), from The Wizard of Oz (1939)

A second pre-rock example, this time taken from Rodgers and Hammerstein's Oklahoma! (1943), illustrates another kind of »apparent stratification. « The melody to $\gg$ C Cain't Say No « is set to a recurring two-measure, four-chord vamp, which acts as a »loop« (Tagg 2016, Nobile 2013). In rock, the presence of such a loop often signals that at least some element of stratification might be present. But as Example 4 shows, that is not the case here. The melody notes are mostly coordinated with the accompanying loop. The only melody note that is not a chord tone is the $C$ over ii ${ }_{5}$ ( $\mathrm{mm} .4$ and 8 in the example), and this is easily seen as a chord tone in the $\mathrm{I}$ and $\mathrm{V}$ chords that frame the harmonic loop. The resulting texture is a coordinated structure.

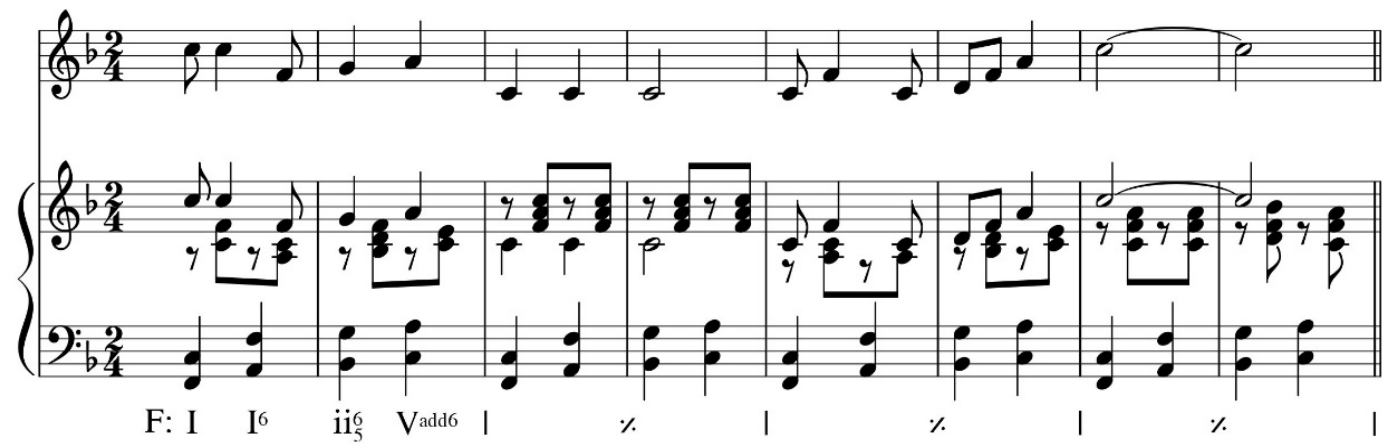

Example 4: »I Cain't Say No« (Rodgers and Hammerstein), from Oklahoma! (1943)

Having now considered examples that are stratified and others that are not, let us examine a few instances that might give rise to different analyses even among those well versed in rock textures. Example 5 provides an analysis of the introduction to the Rolling Stones' »(I Can't Get No) Satisfaction « (1965). The song begins with the famous fuzz-tone guitar riff, tracing out a stepwise melodic path from scale-degree 5 to b7 and back. Against this, the bass moves from the first scale degree to scale-degree 4, creating a moment in which the $D$ in the fuzz guitar sounds above an A in the bass. The acoustic guitar strums the I chord to start, moving to bVII at that D-against-A moment, and then 
moving to the IV chord to produce a double plagal succession when I arrives to re-start the two-measure pattern. Experienced listeners may well differ regarding how coordinated or stratified they find these three parts, especially in light of the moment indicated by the second arrow in Example 5. If one hears this introduction as stratified, each part will be heard to move from a kind of »home base « (first arrow) to an »away place« (second arrow) and back again: the guitar from scale degree 5 to b7 and back, the acoustic guitar from I to bVII and back, and the bass from scale 1 to scale degree 4 and back. The moment indicated by the second arrow is not dissonant from this perspective, but not coordinated either (it is not dissonant precisely because the texture is not coordinated). If one hears the passage as coordinated, then the moment indicated by the second arrow is indeed dissonant in a traditional structural sense, resulting in an unstable bVII ${ }_{4}$ chord, which then resolves into a root-position IV as the acoustic guitar cycles back towards tonic.

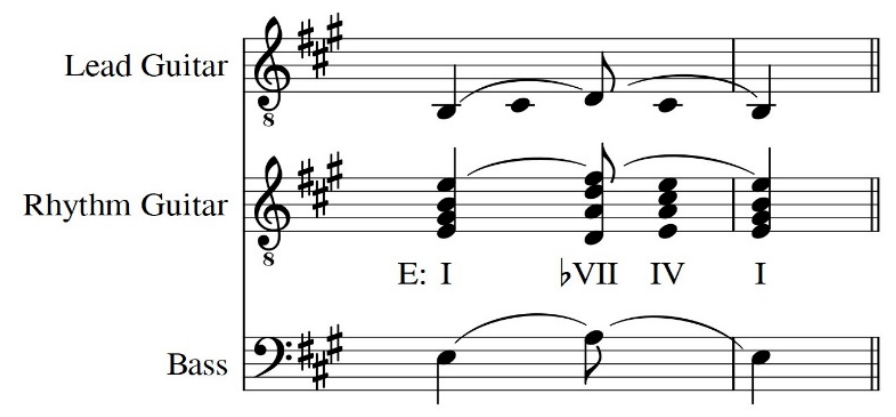

Example 5: The Rolling Stones, »(I Can't Get No) Satisfaction« (1965)

Example 6 shows Walter Everett's (2001) graph of the Beatles' »Help!« (1965). This song employs the »Beatles contrasting verse-chorus « form (Covach 2005 and 2006), which is a contrasting verse-chorus form in which there are two versions of the chorus (usually one at the beginning and a second in the rest of the song). Other instances of this form occur in »She Loves You, « »Can't Buy Me Love, «I'm a Loser, « and even »Eleanor Rigby« (both Lennon and McCartney employed this form). Everett labels the first chorus as »introduction « (see the boxed letter A) and the second version as »chorus « (see the boxed letter $\mathrm{D}$ ), but the similarity between the two is very clear from his graph. Note especially the second chorus, which is enclosed in a box in the example. Lennon's vocal note at the beginning of the chorus is a kind of recitation tone on the fifth scale degree, E. This is a logical extension of Lennon's $\mathrm{C \#}$ recitation tone from the verses; but when the $\mathrm{E}$ arrives at the start of this chorus it is accompanied by the ii chord, a B-minor triad. Everett takes this texture to be coordinated, and this causes him to cast this $\mathrm{E}$ in the melody as an upper neighbor to D, which is indeed consonant with the ii chord. But it is 
also possible to view this passage as partly stratified (in the sense of a melodic-harmonic divorce) and that the $E$ is in fact the important structural tone in the melody in this chorus (not an upper neighbor to D), ultimately working its way down to A at the cadence. Similarly, one can also hear the $E$ as the important note over the following chord, IV (or G major). It is not until the accompaniment arrives at the $\mathrm{V}$ chord (E major) that the $\mathrm{E}$ falls into coordination. If one wanted to combine this latter reading with Everett's to produce a third possible reading, one could take the $E$ as a large-scale anticipation to the structural support provided by the arrival of the $V$ chord. But in either of these latter two cases, the $D$ is less structurally stable than the $E$.
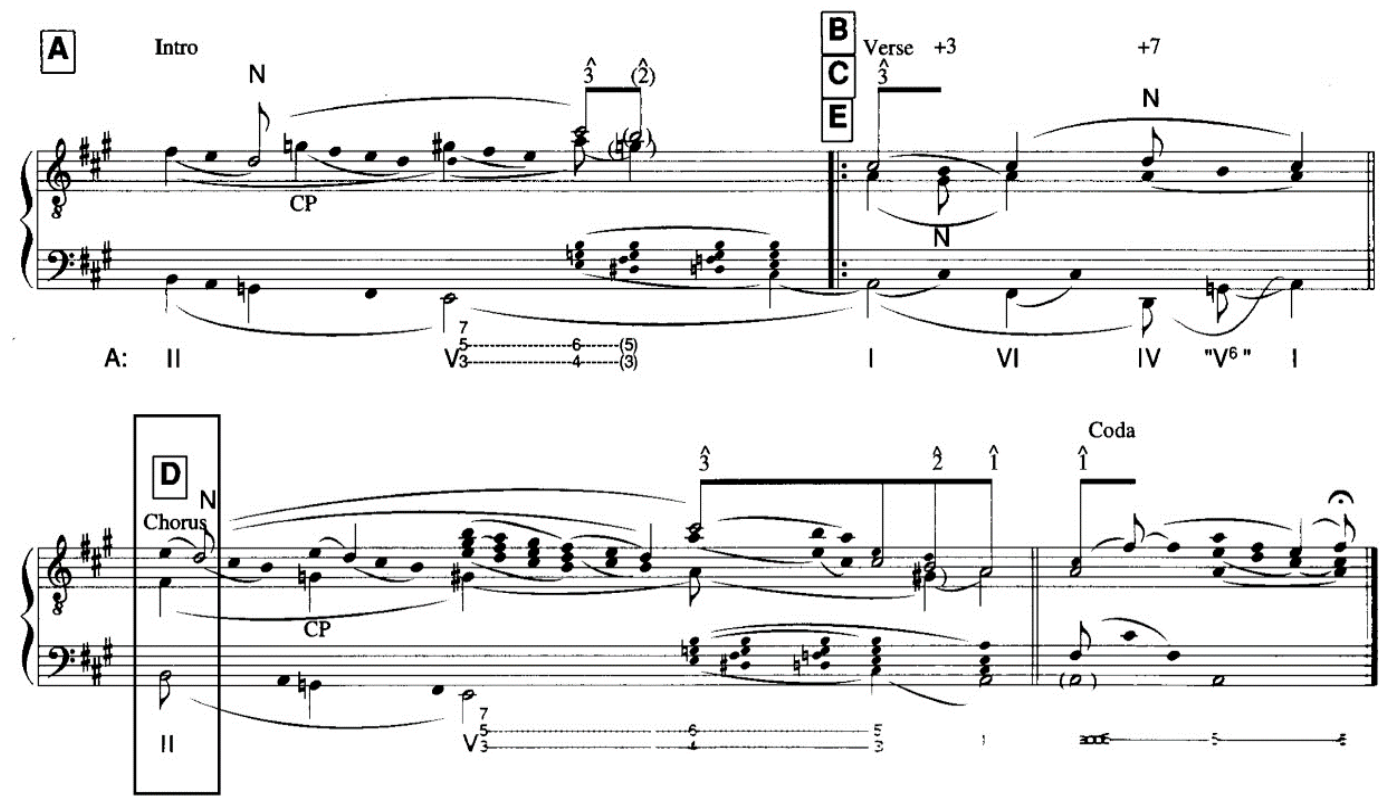

Example 6: The Beatles, »Help!« (1965); Everett (2001)

Example 7 shows Everett's (1999) graph of the Beatles' »Lucy in the Sky with Diamonds« (1967). This song resists analysis in a single key. It is cast in a contrasting verse-chorus form with a pre-chorus. The verse is in A, the prechorus wanders from $B b$ to $D$, and the chorus is mostly in $G$, though ending in A. As one can see in the example, Everett takes the song in $G$ overall. For purposes of our present focus on multiple interpretation, let us pause to consider the pre-chorus, which Everett labels »transition « (enclosed in a box in the example) and explore how Lennon's vocal relates to the harmonies that seem to support it. Once again, the melody is built on a recitation tone-a kind of vocal pedal point-and the chords shift beneath it. As the D sounds in the vocal it is supported by a Bb-major triad, then a C-major triad, and then an F-major triad. The phrase ends with Lennon sliding down to a $\mathrm{Bb}$ as a $\mathrm{Bb}$ major triad returns. He returns to the $D$ against a $C$-major triad, and then against a G-major triad, before moving scale-wise down to A, accompanied 
by a D-major chord. The $D$ in the melody is not always a non-chord tone, but when it is not one of the notes in the chord that supports it, we might wonder if this is a situation similar to the one in »If I Only Had a Brain « discussed above. Are these non-chord notes simply harmonic extensions? It is possible to argue plausibly that they are not harmonic extensions and that this passage is at least partially stratified-that collapsing the melody note into the chord does a certain violence to the texture.

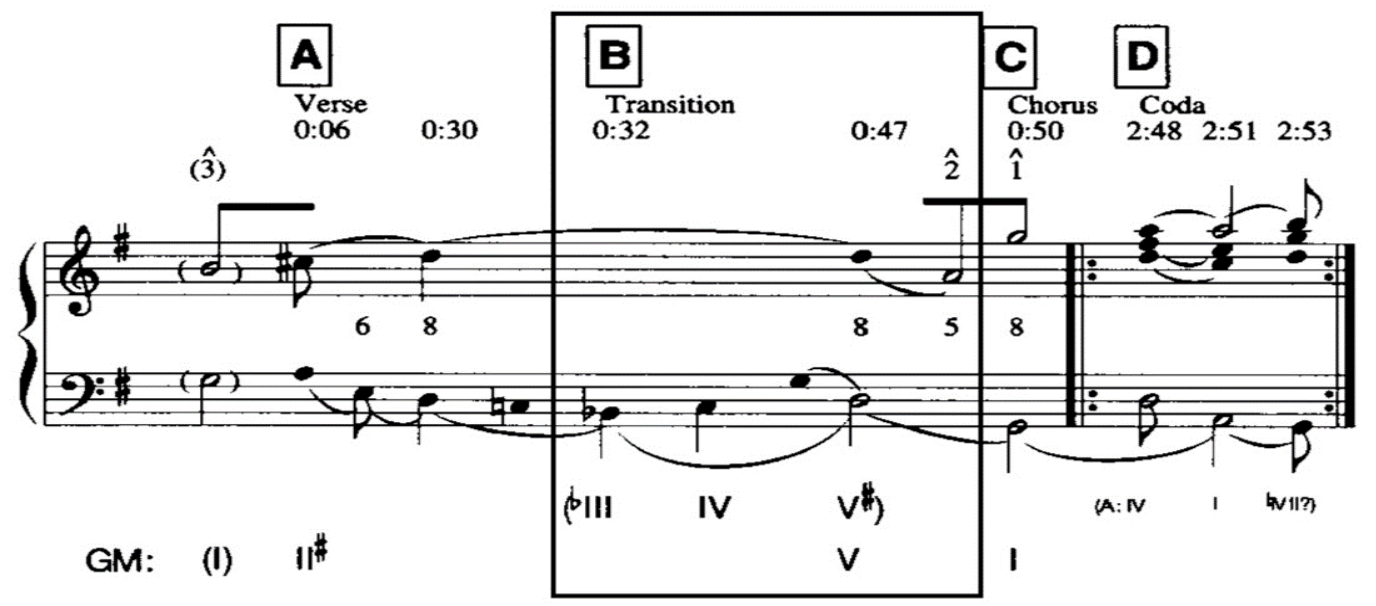

Example 7: The Beatles, »Lucy in the Sky with Diamonds« (1967); Everett (1999)

\section{Points of Coordination, Spans, and Textural Rhythm}

Thus far we have considered two examples where the melodic-harmonic divorce and textural stratification were clear, examined two more examples where one might suspect stratification to be present but is not, and explored three examples that are open to multiple interpretation in terms of texture. Let us turn now to an example where stratification is clear in order to advance our discussion beyond simply identifying when stratification is present, moving to considerations of how stratification can operate once we are confident it is in play.

Example 8 provides a transcribed score for Yes's »Roundabout« (1971), and Example 9 provides an analysis of the relationships between the layers. ${ }^{4}$ We will focus on the first verse of the song, along with the lead-in to the singing for both this first verse and the second verse. The texture is made up

4 The following analysis summarizes points made in Covach (2014). See also Covach $(2013,2016)$. For a discussion of stratification in the music of Benjamin Britten, see Rupprecht (1996). 
of three layers: the bass plays a one-bar ostinato pattern in $\mathrm{E}$ minor, walking up scale-degrees 1,2 , and 3 , and then including a pentatonic flourish up to scale-degree 1 . The guitar employs a progression that moves from $i$ to ii to blll and back, in the Dorian mode and only partially coordinated with the bass. The lead vocal, which is not coordinated with either the guitar or the bass, traces a path up to the second scale degree, perhaps resolving to the first scale degree. The F\# in the vocal melody could easily be heard as the ninth of the chord. But whether one hears this note as a harmonic extension or as an upper neighbor seeking resolution, the question arises: where exactly is the harmony against which the analyst is making that decision? There is no sustained tonic chord in this passage-at least not in the foreground.
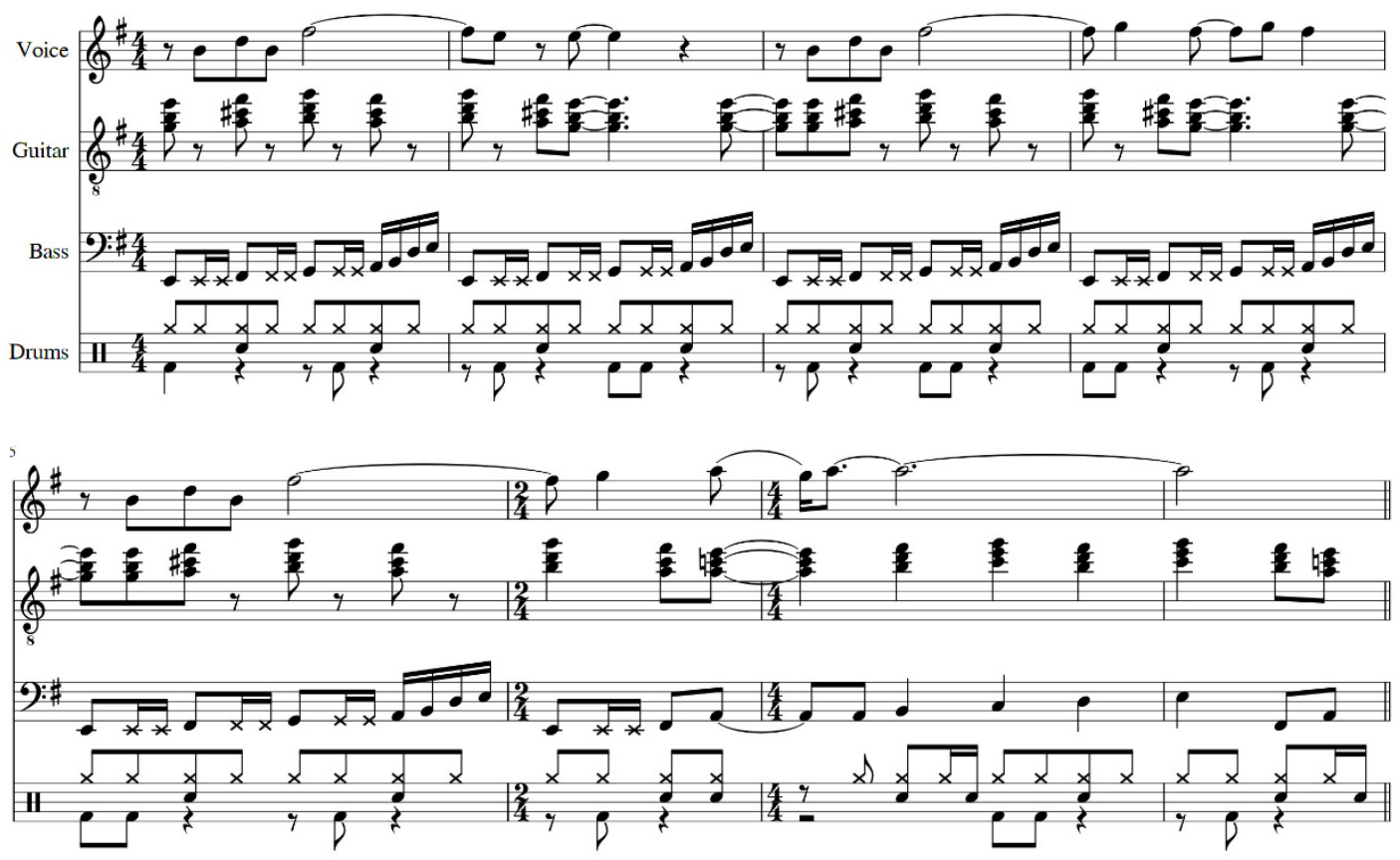

Example 8: Yes, »Roundabout« (1972), transcribed score

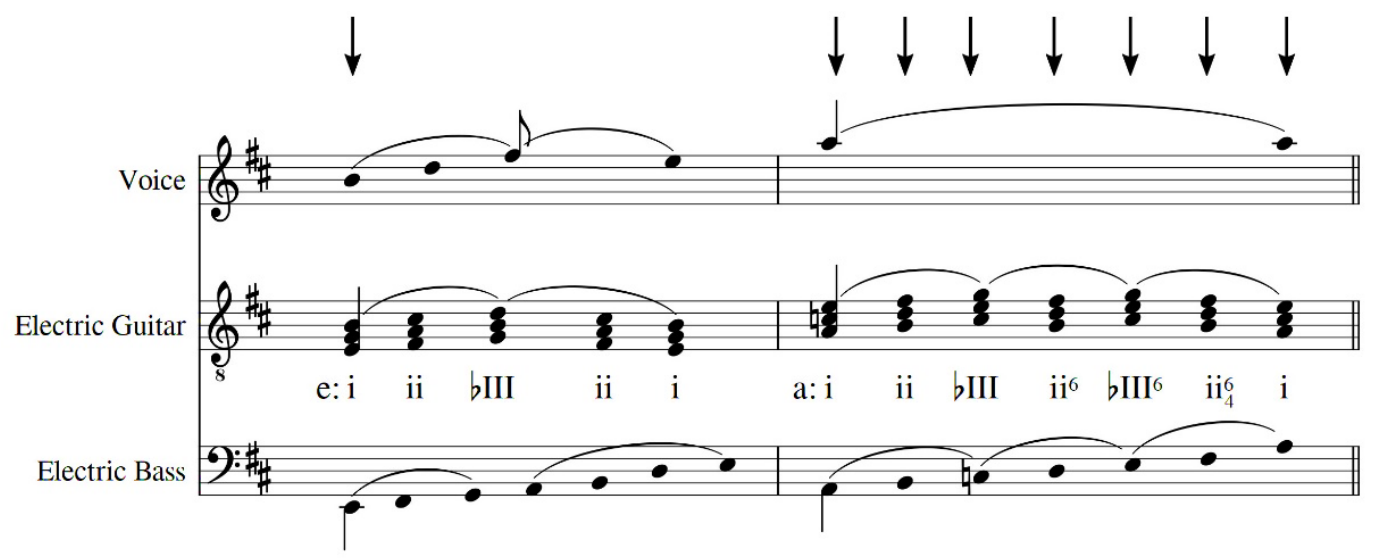

Example 9: Yes, »Roundabout, « stratification and coordination in verse sections 
Up to this point, emphasis in the discussion of stratification has been placed on the absence of coordination; but complete absence of coordination is rarely the case in most rock music in a strict sense. All of the examples considered to be stratified in this article, for instance, are to some extent coordinated in many ways. Most share a common time signature, though even those that do not share a time signature at least share a common pulse. All are also in the same key-when a key can be determined, that is-and the dissonances produced by stratification are often not particularly jarring and are most often constitute some form of pan-diatonicism. Cross relations can be found, but stratification tends to obscure these when they occur between layers, since the specific notes involved frequently do not relate directly to one another. Stratification, then, is perhaps best understood not as an absence of coordination but rather as a looser form of coordination. And once a stratified texture is identified, the next task is to identify the duration of the stratification: is there a point where the levels re-align? In the case of »Roundabout « and Examples 8 and 9, that point initially happens every two measures. We may call this moment of alignment the "point of coordination« and the length of the stratification occurring between points of coordination will be its »span. « To return once more to that F\# in the vocal melody: determining its status as a ninth or as an upper neighbor requires hearing that note against the point of coordination and not necessarily against any specific or individual chord.

The discussion thus far might also have implied that once a section is identified as stratified, it will be found to be stratified throughout that section. This is often not the case, however. A shift between stratified and coordinated passages can occur both between sections and within them. In »Roundabout, «for instance, the stratified two-bar spans described above give way to coordinated material at the end of the verse. In Example 9, an arrow is used to mark the point of coordination in the passage analyzed on the left (the two-bar span). When the harmonic succession $\mathbf{i}$ - ii - blll moves to A minor, note that the bass locks in with the chords in the guitar, and this is shown with a series of arrows marking these points of coordination. With the vocal line holding on to a high A (a melodic pedal tone), this latter passage is clearly coordinated. This shift from stratified to coordinated textures creates a kind of »textural rhythm«-something akin to what Temperley (2007) has identified as »loose verse-tight chorus in his discussion of the melodic-harmonic divorce. In fact, Temperley's scheme is just one of many that can arise in rock music, both within and between sections. 


\section{Degrees of Coordination}

Let us take a moment to consider the range of textures-at least in a theoretical sense-that might be possible. On one end of the spectrum we might imagine the type of coordinated texture we are accustomed to from European common-practice music of the eighteenth and nineteenth centuries. At the other end we place full stratification, which features no point of coordination beyond an initial one; this is simply musical material sounding simultaneously. The progression from coordinated structure to full stratification occurs as coordination is gradually loosened (Covach 2014).

Coordinated structure: Traditional harmonic-contrapuntal texture.

Momentary stratification: Within an otherwise coordinated texture, a brief passage of stratified texture may arise that cannot satisfactorily be normalized according to traditional principles but that does not significantly disrupt the overall coordination of the texture.

Pedal point: Upper parts operate according to traditional principles, but the static part (usually but not always in the bass) is isolated, creating two layers temporarily.

Ostinato: Similar to pedal point, but with notes in the ostinato figure (usually but not always in the bass) relating to one another primarily within that layer, secondarily to the other layer.

Melodic-harmonic divorce: Similar to ostinato, but with a melodic part replacing the ostinato figure as melody; still in two layers: melody and accompaniment.

Textural stratification: Similar to melodic-harmonic divorce, but with accompaniment composed of two, but often also three or more layers.

Full stratification: Layers of simultaneously sounding material with no recurring point of coordination beyond an initial one.

These seven degrees of stratification can be reduced to three, of which two, coordinated structure and textural stratification, are useful for our discussion. The transition point from coordinated structure into textural stratification comes between pedal point and ostinato: 
Coordinated structure: Includes traditional coordination, momentary stratification, and pedal point. Parts and layers are always directly relatable to one another.

Textural stratification: Includes ostinato, melodic-harmonic divorce, and textural stratification; points of coordination create spans.

Full stratification: No coordination or points of coordination beyond an initial one.

\section{Positional Listening and Positional Analysis}

We began this discussion by considering the differences between painting and sculpture and with the possibility of getting inside a musical texture-walking around in it and appreciating it from different angles, with none of these angles constituting a privileged position. Stratified textures allow us to imagine this a little more easily, because textural stratification sometimes makes it difficult to hear everything-and even when we can, we are forced to hear it from an orientation that privileges one layer or another. Positional listening refers to a mode in which we focus on some layer or instrumental part within a texture and hear everything else in relationship to this point of textural focus. In a sense, what we hear depends on where we »stand « (understood in a figurative sense). ${ }^{5}$ The idea that we are able to isolate various »streams « in music as we listen has been much discussed by music cognition scholars, as chronicled by Betsy Marvin (2016). Building on Albert Bregman's work on auditory scene analysis (1990 and 2008; Bregman and McAdams 1979), researchers have explored how we are able to isolate, say, an electric guitar part within a fairly dense texture. The »cocktail party« example is often cited: when speaking with friends at a noisy cocktail party or reception, we are able to isolate the voices of our friends as they speak while simultaneously suppressing the other voices and noise in the room. Research suggests that this is a way of focusing our aural attention-something that people can do quite readily but that is very difficult to program computers to do. Streaming is a complicated and complex cognitive activity that is nevertheless mostly transparent to humans.

5 For discussions of similar approaches, see Berger (1997, 1999), Bruford (2016, 2018), and Klorman (2016). See also Clarke (2005: pp. 91-125 and 182-188 especially) for discussions of listening position and texture that differ in some ways from the ones presented here. 
It is clear that musicians engage in cognitive streaming routinely, both aesthetically (as listeners to music) and in performance. Such positional listening may be defined as the purposeful suppression of some element in a texture to create increased focus on other element(s). The word »purposeful « is employed here because this activity assumes all elements of the texture are available to a listener. ${ }^{6}$ In analysis, we usually assume the Ideal Listening Position (ILP). In fact, we have mostly adopted the ILP in discussing the musical examples presented thus far. Positional analysis, by contrast, tries to capture and examine a sense of textural multi-dimensionality. It is an approach that begins by defining a place within the texture and working out from there. And though we have been focusing primarily on stratified textures in this discussion, positional listening can occur in listening to and performing rock music that is coordinated as well. ${ }^{7}$ Texture stratification makes positional listening more obvious, but positional listening is not restricted to stratified textures.

In order to gain a greater sense of how positional listening can occur in performance, let us return to the example drawn from Yes's »Close to the Edge « (Example 2). The reader may recall that in this passage the electric sitar and vocal are in 12/8, while the electric bass and drums are in 4/2. In terms of meter, the point of coordination between these two layers occurs after the 12/8 layer is played four times and the 4/2 layer is played three times-a span of forty-eight eighth notes. Within the electric sitar and vocal layer, these two parts are stratified in terms of harmony and melody (divorce), with a point of coordination that occurs every two measures of $12 / 8$, creating a span of twenty-four eighth notes. In performance, the guitarist and singer are likely to lock in with one another metrically and mostly suppress the 4/2 meter in the bass and drums. The bassist and drummer, on the other hand, are likely to lock in with one another in 4/2 and suppress the $12 / 8$ in the voice and sitar. The listener, by contrast, is free to opt for a listening position that takes all of this stratification in, perhaps striving for the ILP, much like the producer and recording engineers do in the recording studio or the front-of-house engineer does in a concert setting. It can often occur in live performance that the listening positions of the musicians will each differ from one another while their ensemble performance creates a texture that

6 The reader is reminded that a »position « as employed here is not a physical position such that certain instruments are louder or softer than others by virtue of placement in some physical space. A position here refers to the listener's focus of attention: one achieves a position by focusing on some elements and suppressing others while all elements are available.

7 For a fuller discussion of positional listening and analysis, see Covach (forthcoming). 
can be heard from the ILP. ${ }^{8}$ In addition, just as textures can shift from stratified to coordinated, so too can the performer's listening position shift during the course of a single performance, or even between individual performances of the same song (McCandless 2016). Positional analysis attempts to capture such differences without resolving them into a single position. Position and shifting can be driven by the texture and the demands of performance, but this is not always the case. Positional listening and texture are thus related but distinct.

\section{Analytical Perspectivism}

Much of what is presented above suggests that no single analysis can fully represent the various ways of experiencing and understanding rock music. This argument also challenges the idea that all textures are coordinated and rejects the idea that the Ideal Listening Position is the only valid perspective from which to hear and interpret music. This openness to variant analytical interpretations may be referred to as »analytical perspectivism «-the notion that what you hear depends upon where you stand. The term "perspectivism《 is adapted from its use by the German philosopher Friedrich Nietzsche. In his notebooks that would posthumously be published as The Will to Power, Nietzsche writes:

Against positivism, which halts at phenomena-»There are only facts«-I would say: No, facts is precisely what there are not, only interpretations. We cannot establish any fact »in itself «: perhaps it is folly to want to do such a thing.

»Everything is subjective, « you say; but even this is interpretation. The »subject « is not something given, it is something added and invented and projected behind what there is. - Finally, is it necessary to posit an interpreter behind the interpretation? Even this is invention, hypothesis.

In so far as the word »knowledge « has any meaning, the world is knowable; but it is interpretable otherwise, it has no meaning behind it, but countless meanings. -»Perspectivism« (Nietzsche 1967: 267).

Nietzsche challenged accepted notions and intellectual habits by radically disrupting common assumptions-the sounding out of hollow idols, as he writes in the Preface to Twilight of the Idols. In the case of perspectivism,

8 Of course, a listener can choose to focus on any element in the texture, sometimes following a particular instrument, and at other times skipping around the texture to focus on whatever element captures their interest. 
Nietzsche is advancing the proposition that there are only ever interpretations-no single interpretation can suppress others by appealing to facts. There are only ever perspectives. ${ }^{9}$

The idea that music theorists will tolerate divergent analyses is hardly new, nor is the idea that it is impossible for any single analysis to completely capture a piece or passage of music. ${ }^{10}$ But it may be somewhat more novel to suggest that analyses are inherently incomplete and even prejudiced, with this latter term being used in the positive sense espoused by Hans-Georg Gadamer (1991). There are at least two ways in which perspectivism may apply to musical analysis. The first is when two or more analyses approach the same piece or passage but arrive at differing conclusions, and this is the situation most often found in music theoretical and analytical discussion and debate. Here perspectivism encourages us to hold variant readings in a kind of positive tension, acknowledging that no analysis can attend to every feature or aspect of the music. Indeed, certain analytical approaches develop a more powerful focus as a result (at least in part) from suppressing certain dimensions of the music. This sort of perspectivism applies to the differing analyses of »(I Can't Get No) Satisfaction, «»Help, « and »Lucy in the Sky with Diamonds « discussed above. The second way perspectivism may apply to analysis is when two or more analyses of the same piece or passage, arising from different listening positions, provide differing but complementary analyses. In this second case, the possibility of analytical perspectives arising from inside the texture opens up a third dimension to musical understanding, as was suggested by the analyses of »Roundabout « and »Close to the Edge. «

As soon as one admits the validity of multiple interpretations, however, the slippery slope of relativism presents itself. If analysis is all interpretation, one might object, is any analysis valid, no matter how bad or demonstrably incorrect it may be? What, indeed, might »bad« or »incorrect « even mean in such a context? Perspectivism need not necessarily level the field of analytical value, making every analysis just as valid, useful, or convincing as any other. An analysis, for instance, that takes the passage from »Rock'n Me« discussed above as a coordinated structure can still be rejected. Perspectivism is rather most valuable in its use of a different metaphor for musical understanding and analysis. As suggested at the start of this discussion, a piece is not so much like a painting, to be viewed from some ideal location; it is rather more like sculpture or architecture, which can produce many complementary perspectives. In terms of musical texture and the discussion at

9 For a fuller discussion of analytical perspectivism in the context of organicism and the theoretical writing of Arnold Schönberg, see Covach (2017).

10 For a fuller discussion of this issue, see Dunsby (1994) and Guck (2006). 
hand, the analyst »steps inside « the piece (literally and figuratively), transforming a musical experience from the usual two dimensions into one of three-dimensional richness and depth.

\section{Bibliography}

Berger, Harris M. (1997). »The Practice of Perception. Multi-Functionality and Time in the Musical Experiences of a Heavy Metal Drummer.«In: Ethnomusicology 41 (3), pp. 464-488.

Berger, Harris M. (1999). Metal, Rock, and Jazz: Perception and the Phenomenology of Musical Experience. Hanover, NH: Wesleyan University Press.

Bregman, Albert S. (1990). Auditory Scene Analysis: The Perceptual Organization of Sound. Cambridge, MA: MIT Press.

Bregman, Albert S. (2008). »What Is Auditory Scene Analysis?«, http://webpages. mcgill.ca/staff/Group2/abregm1/web/asa.htm, access: 16 August 2017.

Bruford, William (2016). Making It Work: Creative Music Performance and the Western Kit Drummer. PhD dissertation, University of Surrey.

Bruford, William (2018). Uncharted: Creativity and the Expert Drummer. Ann Arbor, MI: University of Michigan Press.

Clarke, Eric F. (2005). Ways of Listening: An Ecological Approach to the Perception of Musical Meaning. New York: Oxford University Press.

Covach, John (1997). »Yes, >Close to the Edge, Understanding Rock, Ed. by John Covach and Graeme Boone. New York: Oxford University Press, pp. 3-31.

Covach, John (2005). »Form in Rock Music: A Primer.«In: Engaging Music: Essays in Music Analysis. Ed. by Deborah Stein. New York: Oxford University Press, p. 6576.

Covach, John (2006). »From Craft to Art: Formal Structure in the Music of the Beatles. « In: Reading the Beatles: Cultural Studies, Literary Criticism, and the Fab Four, Ed. by Ken Womack and Todd F. Davis, Albany, NY: SUNY Press, pp. 37-53.

Covach, John (2013). »Yes's >Heart of the Sunrise <: Textural Stratification and Formal Fragmentation. « Paper presented at the Annual Conference of the Society for Music Theory (Charlotte, NC), 1 November.

Covach, John (2014). »Textural Stratification in Rock Music. "Video posted by the University of Rochester Institute for Popular Music, https://youtu.be/of3UxtvvmAQ.

Covach, John (2016). »A View from Guitar Land: Shifting Positional Listening in Complex Textures. « Paper presented at Annual Conference of the Society for Music Theory (Vancouver, BC), 3 November.

Covach, John (2017). "Schoenberg's (Analytical) Gaze: The Aesthetics of Organicism. «In: Theory and Practice 42, pp. 141-159.

Covach, John (forthcoming). »The Performer's Experience: Positional Listening and Positional Analysis. «In: Investigating Music Performance: Towards a Conjunction of Ethnographic and Historiographic Perspectives. Ed. by Gianmario Borio and Giovanni Giuriati. Milton Park and New York: Routledge.

Dunsby, Jonathan (1989). »Considerations of Texture. «In: Music and Letters 70 (1), pp. 46-57. 
Dunsby, Jonathan (1994). »Criteria of Correctness in Music Theory and Analysis. «In: Theory, Analysis, and Meaning in Music. Ed. by Anthony Pople. Cambridge: Cambridge University Press, pp. 77-85.

Everett, Walter (1999). The Beatles as Musicians: Revolver through the Anthology. New York: Oxford University Press.

Everett, Walter (2001). The Beatles as Musicians: The Quarry Men through Rubber Soul. New York: Oxford University Press.

Gadamer, Hans-Georg (1991). Truth and Method. New York: Crossroad $\left(2^{\text {nd }}\right.$ revised ed.). London, UK et al.: Bloomsbury.

Guck, Marion A. (2006). »Analysis as Interpretation: Interaction, Intentionality, Invention. «In: Music Theory Spectrum 28 (2), pp. 191-209.

Klorman, Edward (2016). Mozart's Music of Friends: Social Interplay in the Chamber Works. Cambridge: Cambridge University Press.

Marvin, Elizabeth W. (2016). „Positional Listening as Prioritized Integrative Attention. «Paper presented at Annual Conference of the Society for Music Theory (Vancouver, BC), 3 November.

McAdams, Stephen / Bregman, Albert (1979). »Hearing Musical Streams. «In: Computer Music Journal 3 (4), pp. 26-43, 60.

McCandless, Gregory (2016). »Attentional Cost and Positional Analysis: A Bassist's Perspective. "Paper presented at the Annual Conference of the Society for Music Theory (Vancouver, BC), 3 November.

Moore, Allan (1995). »The So-Called >Flatted Seventh in Rock Music.«In: Popular Music 14 (2), pp. 185-201.

Nietzsche, Friedrich (1967). The Will to Power. Ed. by Walter Kaufmann. New York: Vintage.

Nobile, Drew (2013). »Further Thoughts on the Melodic-Harmonic Divorce.«Paper presented at the Annual Meeting of the Society for Music Theory (Charlotte, NC), 31 October.

Rupprecht, Philip (1996). "Tonal Stratification and Uncertainty in Britten's Music.« In: Journal of Music Theory 40 (2), pp. 311-46.

Tagg, Philip (2016). Everyday Tonality II. Version 2.6.3. New York and Huddersfield: The Mass Media Music Scholar's Press.

Temperley, David (2007). »The Melodic-Harmonic Divorce in Rock. «In: Popular Music 26 (2), pp. 323-342.

Van der Merwe, Peter (1989). Origins of the Popular Style: The Antecedents of Twentieth-Century Popular Music. New York: Oxford University Press.

Winkler, Peter (1978). »Toward a Theory of Pop Harmony. «In: In Theory Only 4, pp. 3-26. 


\begin{abstract}
This article considers musical texture as an aspect of structure, examining first how elements in a texture may relate to one another, and then exploring how the analyst may develop a variety of perspectives by privileging certain elements in the texture over others. Traditional classical music textures are coordinated, and the traditional analytical perspective employs the Ideal Listening Position (ILP). Some popular music, however, may employ layered textures, which manifest varying degrees of textural stratification. The ideas of point of coordination and span are developed as a way of analyzing textural rhythm and mapping variations in the level of coordination that may occur both within and between sections in a given piece. Stratified music encourages positional listening, particularly in performance, and such positions tend to differ from the tradition ILP. Positional analysis attempts to capture such variant positions and analytical perspectivism provides a lens for considering how such differences may be reconciled (or not).
\end{abstract}

